\title{
Influence of Non-Equiaxed Microstructure on the Superplastic Behavior of the Pb-Sn Eutectic
}

\author{
By B. P. Kashyap* and G. S. Murty*
}

\begin{abstract}
The superplastic behavior and changes in microstructural parameters were studied in the $\mathrm{Pb}-\mathrm{Sn}$ eutectic alloy with initially banded structures and grains elongated in one or two directions. These microstructures were obtained by an appropriate thermomechanical processing of the cast alloy. The flow stress was observed to depend on the direction of loading relative to the bands or elongated grains. Furthermore, there was strain dependency of flow stress at a given strain rate unlike the usual steady state flow behavior of superplastic deformation. This was accompanied by the break up of the non-equiaxed microstructure leading to the evolution of equiaxed structure with increasing strain.
\end{abstract}

(Received November 13, 1980)

\section{Introduction}

Superplastic behavior of materials is of considerable interest from the viewpoint of deformation processing as well as in understanding the high temperature deformation behavior of materials $^{(1)(2)}$. In order to observe structural superplasticity, ultrafine microstructure with equiaxed grains is well recognized to be an important requirement. This is often met by heavy deformation processing of the cast alloys such as eutectics. In such cases there could be varieties of microstructures from fully equiaxed grains to elongated grains along with clustering of grains of different phases depending on the details of processing history. From the viewpoint of assessing the mechanisms of superplastic flow, fully equiaxed grains whose size is stable during flow would be simpler to deal with than more complicated microstructures. In the as-worked state, it has been observed that there is microstructural instability leading to strain dependency of flow stress $^{(3)(4)}$. In such cases the evolution of microstructure during the superplastic deformation is of major interest in understanding the role of microstructural parameters in superplasticity. The details of the influence of microstructural features on the superplastic behavior will be of significance especially in commercially

* Department of Metallurgical Engineering, Indian Institute of Technology, Kanpur, India. exploiting superplasticity as a forming process. It is with this general aim that the present investigation was taken up. $\mathrm{Pb}-\mathrm{Sn}$ eutectic alloy specimens were specially processed to deliberately produce banded structures as well as elongated grains. Their superplastic behavior and the changes in microstructural parameters were studied.

\section{Experimental Procedure}

$\mathrm{Pb}-\mathrm{Sn}$ alloy of nominal eutectic composition was prepared from tin and lead, both of $99.99 \%$ purity. Melting of the alloy was done by heating the required charge in a vacuum sealed pyrex tube. In order to avoid the pipe formation in the ingot, it was subsequently remelted in air and cast into a pyrex tube with a heat sink at the bottom. These ingots were then homogenized at $160^{\circ} \mathrm{C}$ for $72 \mathrm{~h}$ in an electrically heated silicone oil bath. The following thermomechanical treatments were adopted to obtain different microstructures.

\section{Banded structure}

The cast ingot of $75 \mathrm{~mm}$ diameter was extruded to $47 \mathrm{~mm}$ diameter and then annealed at $170^{\circ} \mathrm{C}$ for nearly $30 \mathrm{~d}$ in silicone oil bath. This ingot with relatively large grains was further extruded to $12.5 \mathrm{~mm}$ diameter rods. It was followed by swaging to $7.5 \mathrm{~mm}$ diameter rods. All the mechanical working operations were done at room temperature. Specimens thus processed, exhibited banded structures. 


\section{Elongated grains}

(i) The cast ingot of $75 \mathrm{~mm}$ diameter was extruded at room temperature to a $12.5 \mathrm{~mm}$ diameter rod which was further swaged to a final diameter of $7.5 \mathrm{~mm}$. This processing resulted in a microstructure with linear orientation $^{(5)}$ having grain elongation along the rod axis.

(ii) Flat specimens were obtained with elongation of grains in two directions, termed as planar-linear orientation ${ }^{(5)}$ in the following manner. Starting with a flat ingot of $50 \mathrm{~mm}$ thickness, it was rolled to $25 \mathrm{~mm}$ thickness at room temperature and annealed at $160^{\circ} \mathrm{C}$ for $30 \mathrm{~d}$. It was then further rolled to $5 \mathrm{~mm}$ thickness.

Round tensile specimens of $4 \mathrm{~mm}$ diameter and flat tensile specimens of $5 \mathrm{~mm} \times 5 \mathrm{~mm}$ cross section, both with a gauge length of $25 \mathrm{~mm}$, were obtained from the material processed in the above manner. A few compression tests were also carried out using cylindrical specimens of $9 \mathrm{~mm}$ length and $6 \mathrm{~mm}$ diameter. All specimens were tested in an Instron machine using constant crosshead speed and differential strain rate $^{(6)}$ tests at various test temperatures upto $170^{\circ} \mathrm{C}$ by employing an electrically heated silicone oil bath.

Metallographic observations in the longitudinal as well as transverse sections were made as per the usual procedures making use of an etchant consisting of a $4: 1: 1$ mixture of glycerol, acetic acid and nitric acid. The use of fresh etchant was found to be necessary for better results each time.

\section{Results}

\section{Banded structures}

While the distribution of phases was uniform in the transverse section, there was clustering of lead rich grains along the rod axis of these specimens. Typical longitudinal and transverse microstructures of these specimens are shown in Photo. 1. The characterization of the banded structures was done in terms of the intercept lengths in the transverse section $\left(b_{\mathrm{T}}\right)$, as well as

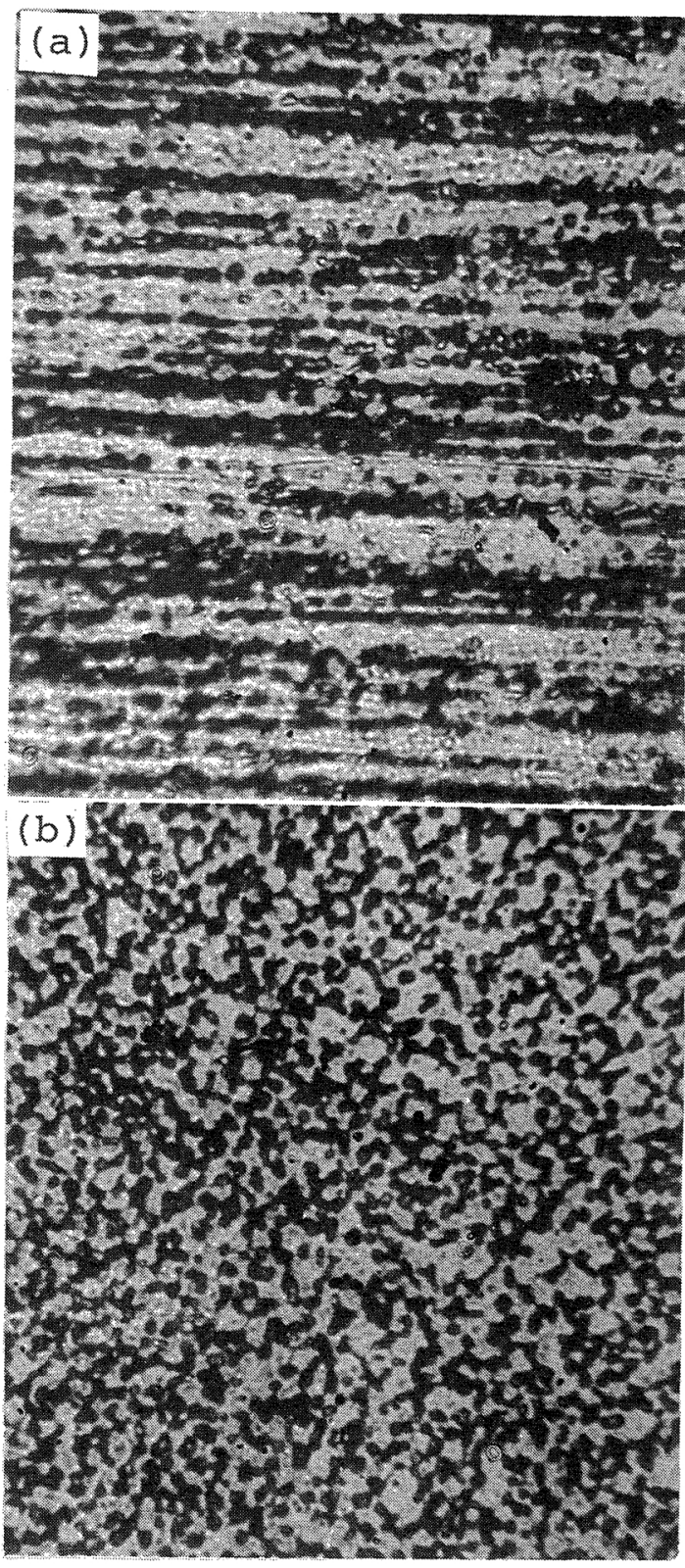

Photo. 1 Longitudinal (a) and transverse (b) microstructures of a specimen with banded structure $(\times 500)$.

band length $\left(b_{\|}\right)$and band width $\left(b_{\perp}\right)$ in the longitudinal section.

Compression specimens at orientations of $0^{\circ}, 45^{\circ}$ and $90^{\circ}$ with respect to the extruded rod axis were tested to assess the strength anisotropy. From the data shown in Fig. 1, it may be noted that their flow stress is orienta- 


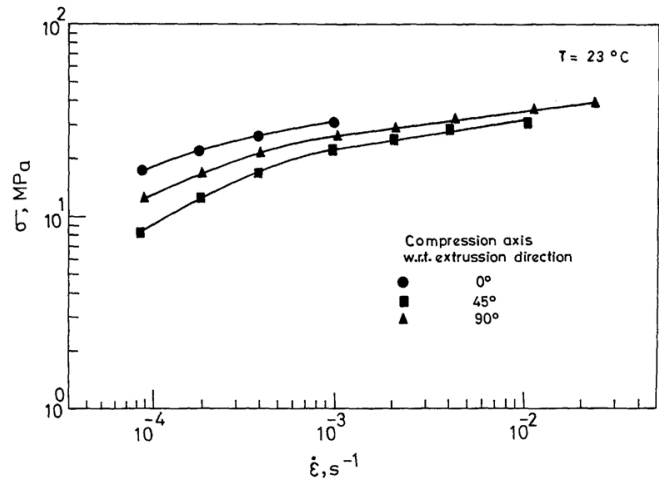

Fig. 1 Anisotropy in $\sigma-\dot{\varepsilon}$ behavior of specimens with banded structure.

tion dependent with a minimum for $45^{\circ}$ orientation. The tensile stress $(\sigma)$-strain rate $(\dot{\varepsilon})$ data of these specimens tested along the rod axis at various test temperatures are shown in Fig. 2, whereas the corresponding strain rate sensitivity index $(\mathrm{m})$ data as a function of strain rate are shown in Fig. 3.

The strain effects on the flow stress and microstructure were studied through repeated strain rate cycling and constant crosshead speed tests. Figure 4 shows the $\sigma-\dot{\varepsilon}$ data obtained by repeated strain rate cycling upto six cycles at $148^{\circ} \mathrm{C}$. While the strain rate sensitivity index was not affected due to cycling, there was some increase in flow stress at a given strain rate. From constant crosshead speed tests at $148^{\circ} \mathrm{C}$, it was observed that there was a slight increase in flow stress upto some strain and

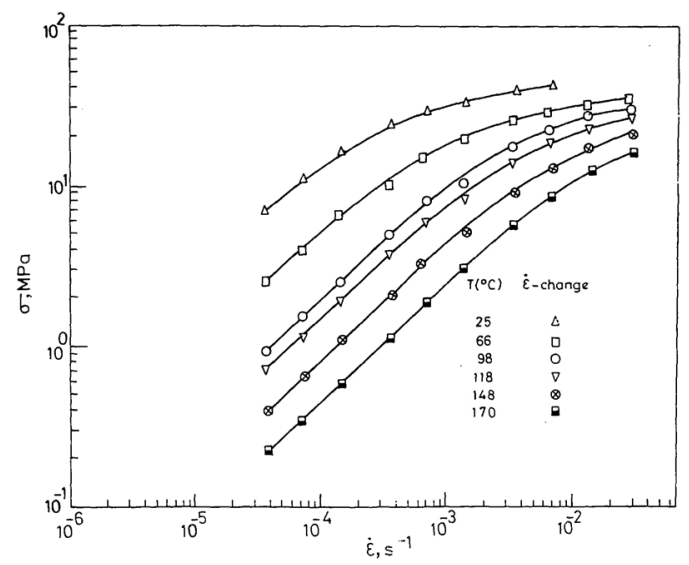

Fig. $2 \sigma-\dot{\varepsilon}$ hehavior of specimens with banded structure $\left(b_{\|}=23.5 \pm 2.8 \mu \mathrm{m}, \quad b_{\perp}=4.9 \pm 0.2 \mu \mathrm{m}, \quad b_{\mathrm{T}}=\right.$ $4.8 \pm 0.6 \mu \mathrm{m})$.

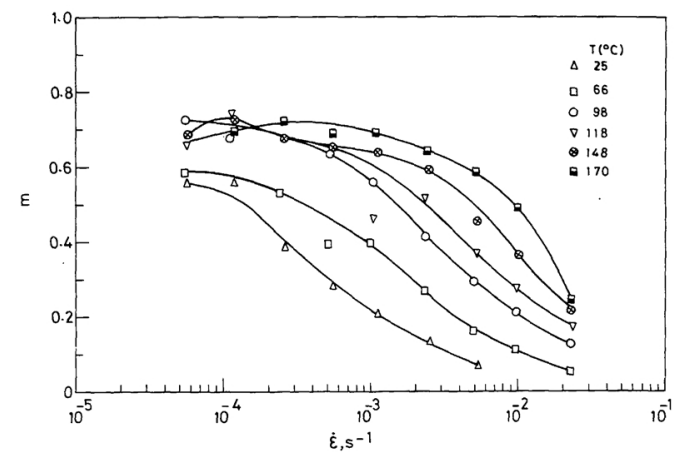

Fig. $3 m$ vs $\dot{\varepsilon}$ plots for specimens with banded structure.

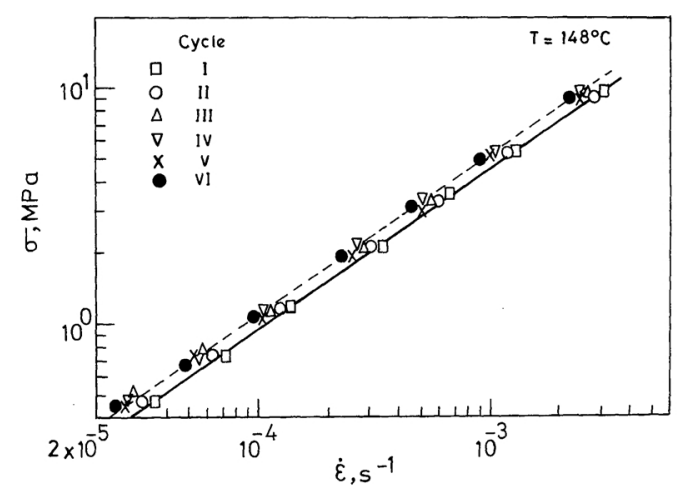

Fig. 4 Effect of repeated strain rate cycling on $\sigma-\dot{\varepsilon}$ behavior of a specimen with initially banded structure $\left(b_{\|}=32.3 \mu \mathrm{m}, b_{\perp}=6.0 \mu \mathrm{m}, b_{\mathrm{T}}=5.8 \mu \mathrm{m}\right)$.

subsequently it became independent of strain. The banded structure was observed to break up with increasing superplastic deformation as illustrated in Photo. 2. The microstructural parameters as a function of strain are given in Table 1. The data of the grip section of tensile specimens which indicate the changes due to annealing for the periods involved in tensile testing are also presented in Table 1 . The ratio of band length to width decreased with increasing strain, while the corresponding change in the grip section was much less. As in the case of linearly elongated grains, the extent of banding in these structures may be characterized by the degree of orientation ${ }^{(5)}$ defined by

$$
W_{\text {or }}(\%)=\frac{100\left[\left(N_{\mathrm{L}}\right)_{\perp}-\left(N_{\mathrm{L}}\right)_{\|}\right]}{0.273\left(N_{\mathrm{L}}\right)_{\|}+\left(N_{\mathrm{L}}\right)_{1}}
$$

where $N_{\mathrm{L}}$ is the number of bands per unit 

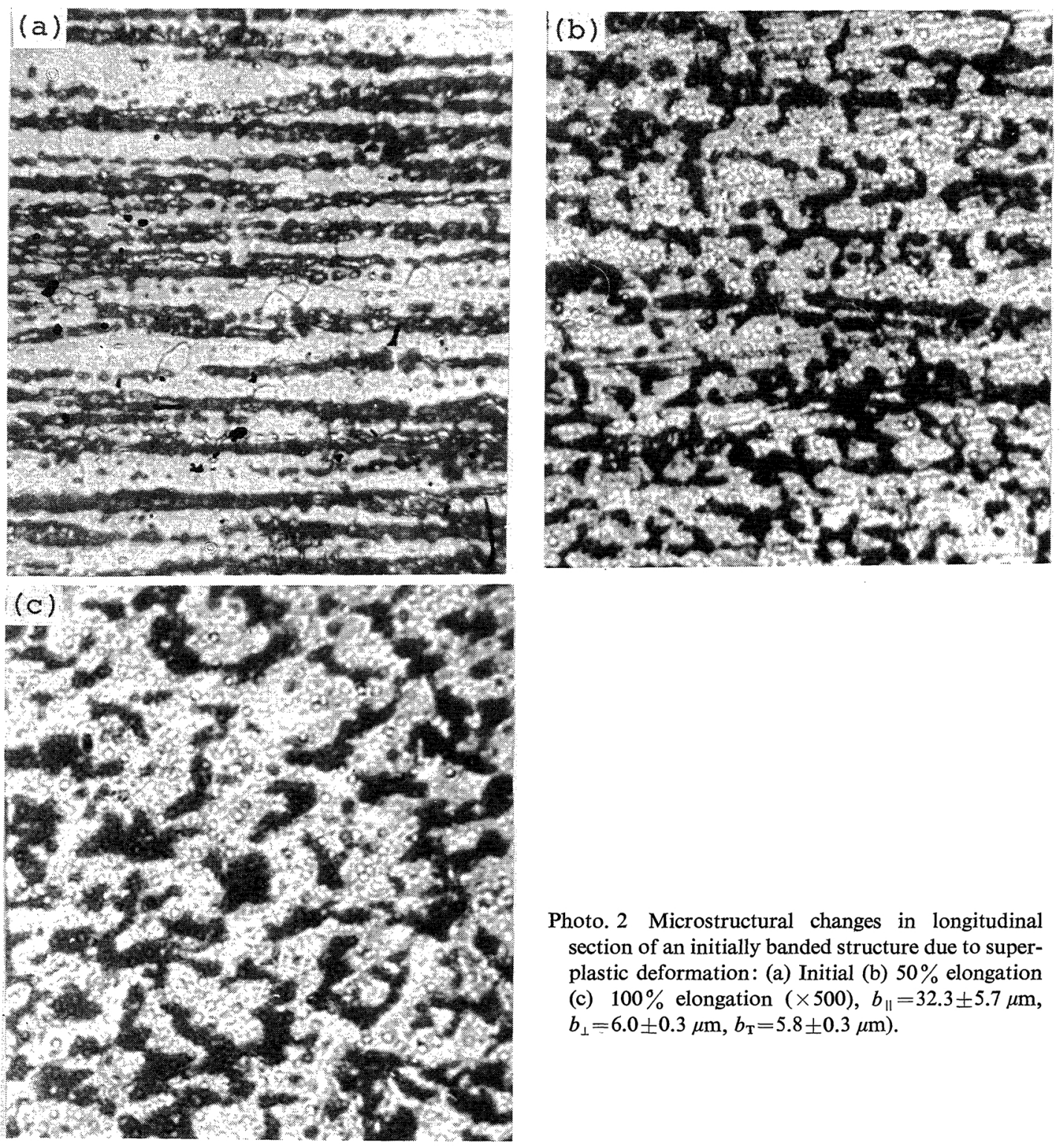

Photo. 2 Microstructural changes in longitudinal section of an initially banded structure due to superplastic deformation: (a) Initial (b) $50 \%$ elongation (c) $100 \%$ elongation $(\times 500), b_{\|}=32.3 \pm 5.7 \mu \mathrm{m}$, $\left.b_{\perp}=6.0 \pm 0.3 \mu \mathrm{m}, b_{\mathrm{T}}=5.8 \pm 0.3 \mu \mathrm{m}\right)$.

Table 1 Changes in microstructural parameters of banded structure due to superplastic deformation. $\left(T=148^{\circ} \mathrm{C}, \dot{\varepsilon}_{\text {initial }}=1.5 \times 10^{-3} \mathrm{~s}^{-1}\right)$.

\begin{tabular}{|c|c|c|c|c|c|c|c|}
\hline \multirow{3}{*}{$\begin{array}{l}\text { Elongation } \\
(\%)\end{array}$} & \multicolumn{3}{|c|}{$\begin{array}{l}\text { Band intercept lengths } \\
\text { in gauge section }(\mu \mathrm{m})\end{array}$} & \multicolumn{2}{|c|}{$b_{\|} / b_{\perp}$} & \multicolumn{2}{|c|}{$\begin{array}{l}\text { Degree of orien- } \\
\text { tation } W_{\text {or }}(\%)\end{array}$} \\
\hline & \multicolumn{2}{|c|}{ Longitudinal } & \multirow{2}{*}{$\begin{array}{l}\text { Transverse } \\
b_{\mathrm{T}}\end{array}$} & \multirow{2}{*}{ Gauge } & \multirow{2}{*}{ Grip } & \multirow{2}{*}{ Gauge } & \multirow{2}{*}{ Grip } \\
\hline & $b_{\|}$ & $b_{\perp}$ & & & & & \\
\hline $\begin{array}{r}0 \\
50 \\
425\end{array}$ & $\begin{array}{l}32.3 \pm 5.7 \\
11.2 \pm 1.0 \\
12.4 \pm 0.7\end{array}$ & $\begin{array}{l}6.0 \pm 0.3 \\
7.4 \pm 0.3 \\
9.3 \pm 0.7\end{array}$ & $\begin{array}{l}5.8 \pm 0.3 \\
7.0 \pm 0.4 \\
8.5 \pm 0.4\end{array}$ & $\begin{array}{l}5.4 \\
1.5 \\
1.3\end{array}$ & $\begin{array}{l}5.4 \\
3.2 \\
3.2\end{array}$ & $\begin{array}{l}74.9 \\
27.2 \\
19.2\end{array}$ & $\begin{array}{l}74.9 \\
61.6 \\
61.5\end{array}$ \\
\hline
\end{tabular}

$b_{\|}=$Band length measured parallel to tensile axis in longitudinal section.

$b_{\perp}=$ Band width measured perpendicular to tensile axis in longitudinal section.

$b_{\mathrm{T}}=$ Intercept length in transverse section. 
length and the subscript $\|$ refers to secants drawn parallel to the tensile axis in the longitudinal section, $\perp$ refers to secants drawn perpendicular to the tensile axis in longitudinal section and 1 refers to secants drawn in the transverse section where the grains appear to be equiaxed. It may be seen from Table 1 that the degree of orientation thus calculated decreases with increasing strain.

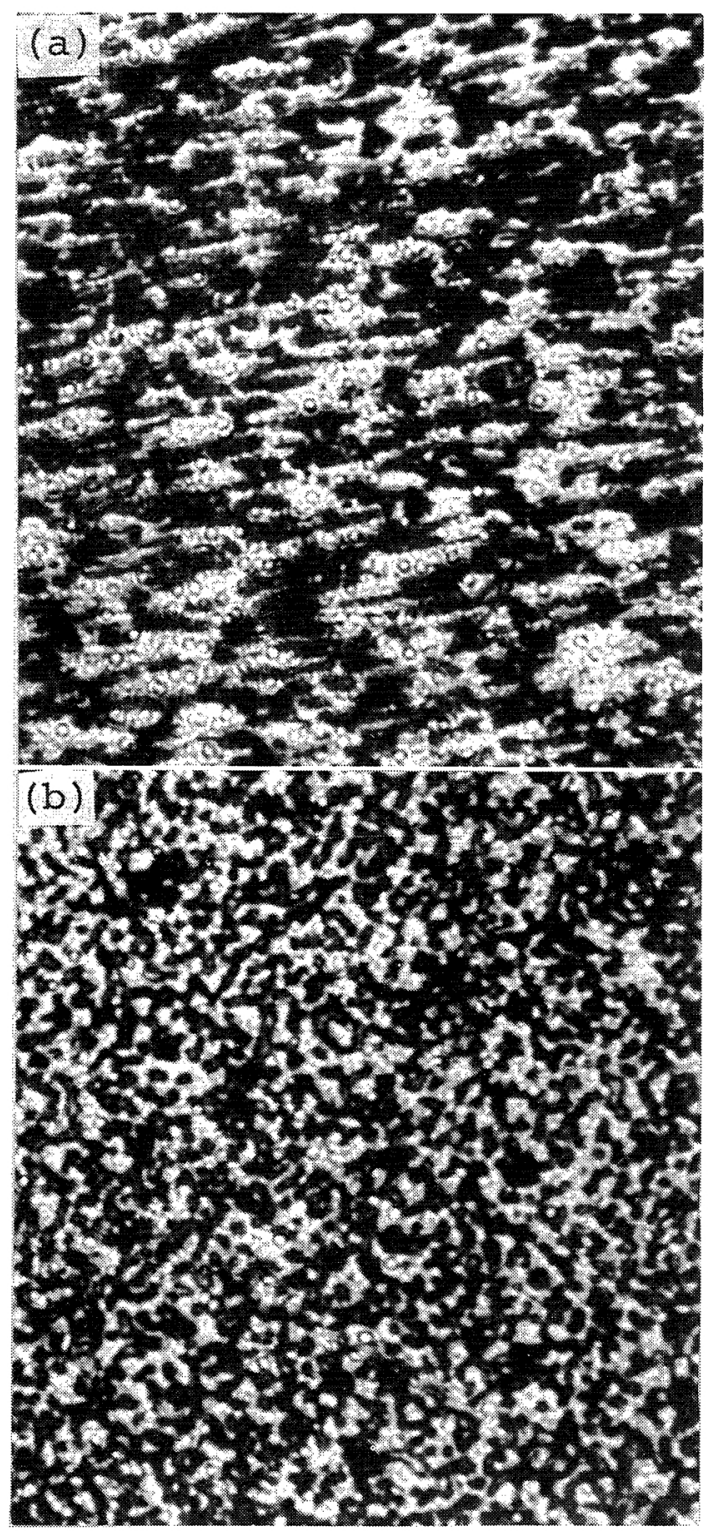

Photo. 3 Longitudinal (a) and transverse (b) microstructures of a specimen having a microstructure with linear orientation $(\times 500)$.

\section{Elongated grains}

The behavior of specimens with two different types of elongated grains is described below separately.

\section{(1) Microstructures having linear orientation of grains}

These specimens have distinct grain elongation along the tensile axis, but in the transverse section the grains appear equiaxed as shown in Photo. 3. The microstructural characterization was done by measuring intercept lengths $l_{\|}, l_{\perp}$, and $l_{\mathrm{T}}$. The initial grain aspect ratio, $l_{\|} / l_{\perp}$ was found to be 1.94 and the degree of orientation as defined in eq. (1) was $33.4 \%$. Their tensile $\sigma-\dot{\varepsilon}$ data are shown in Fig. 5 and the corresponding $m$ versus $\dot{\varepsilon}$ data are presented in Fig. 6. The effects of strain on the flow stress and the microstructural parameters

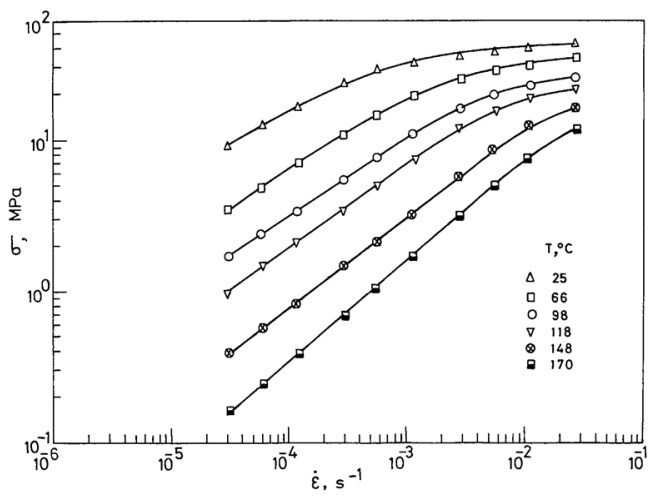

Fig. $5 \sigma-\dot{\varepsilon}$ behavior of specimens having a microstructure with linear orientation $\left(l_{\|}=11.1 \pm 0.7\right.$ $\left.\mu \mathrm{m}, l_{\perp}=5.7 \pm 0.3 \mu \mathrm{m}, l_{\mathrm{T}}=4.4 \pm 0.1 \mu \mathrm{m}\right)$.

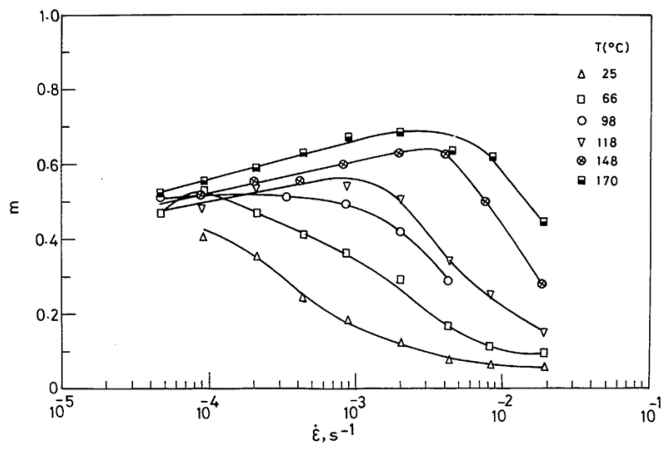

Fig. $6 m$ vs $\dot{\varepsilon}$ plots for specimens having a microstructure with linear orientation. 
were studied. Depending on the test temperature, there was strain hardening or softening up to some strain beyond which the flow stress was independent of strain. The initially elongated grains were also seen to change towards equiaxed shape with increasing superplastic deformation.

\section{(2) Microstructures having planar-linear orientation of grains}

These specimens have grains elongated in two directions viz. along the length and width of the rolled sheet. The intercept lengths in longitudinal section parallel to rolling direction, $l_{\|}$, and perpendicular to the rolling direction, $l_{\perp}$, were measured. In the transverse section, the grains are elongated along the width of the rolled sheet and therefore the measurements of intercept length in directions parallel to width, $l_{\mathrm{w}}$, and parallel to the thickness, $l_{1}$, of the rolled sheet were made. The value of $l_{\mathrm{w}}$ was observed to be equal to $l_{\perp}$.

Tensile specimens were prepared such that their gauge lengths were along $0^{\circ}, 45^{\circ}$ and $90^{\circ}$ to the rolling direction. These specimens of different orientations were tested by the repeated strain rate cycling test at $25^{\circ} \mathrm{C}$ and $148^{\circ} \mathrm{C}$. The flow stress values obtained from the second cycle were found to be lower than those of the first cycle in all cases. The extent of softening was observed to vary depending on the test temperature and orientation with respect to the rolling direction. The extent of softening was more at $148^{\circ} \mathrm{C}$ than that at $25^{\circ} \mathrm{C}$. It was maximum for $0^{\circ}$ orientation and minimum for $45^{\circ}$ orientation. The $\sigma-\dot{\varepsilon}$ data on these specimens at $148^{\circ} \mathrm{C}$ are shown in Fig. 7 and only the first cycle data are shown here for the sake of clarity. The $m$ versus $\dot{\varepsilon}$ data for the first and second cycles are given in Fig. 8 in the case of $0^{\circ}$ and $90^{\circ}$ orientations.

Constant crosshead speed tests were also performed at room temperature for the above three orientations. From the stress-strain curves of these specimens shown in Fig. 9, it can be noted that the specimen of $45^{\circ}$ orientation exhibits minimum flow stress while it is maximum for $0^{\circ}$ orientation. The flow stress was observed to be same for all orientations after about $135 \%$ elongation. Strain softening

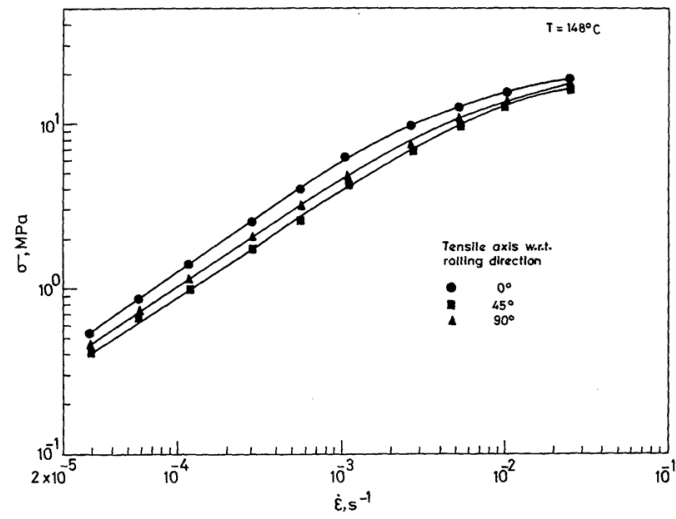

Fig. 7 Anisotropy in $\sigma-\dot{\varepsilon}$ behavior of specimens with microstructures having planar-linear orientation.

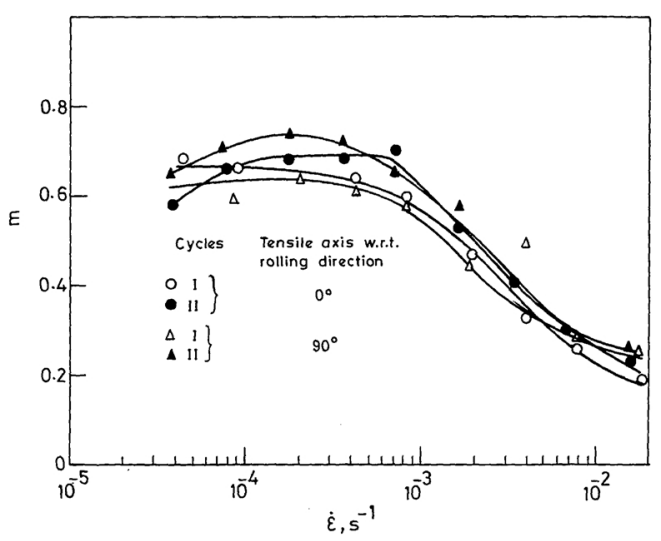

Fig. 8 Effect of repeated strain rate cycling on $m$ vs $\dot{\varepsilon}$ data of specimens with planar-linear orientation of grains.

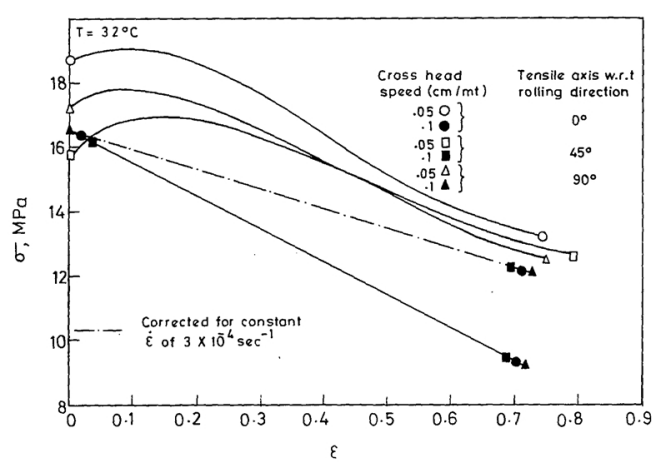

Fig. 9 Stress-strain curves of specimens with planarlinear orientation of grains.

was observed in all the three cases. Photograph 4 shows the initial microstructures and those after deformation for a specimen of $0^{\circ}$ orienta- 

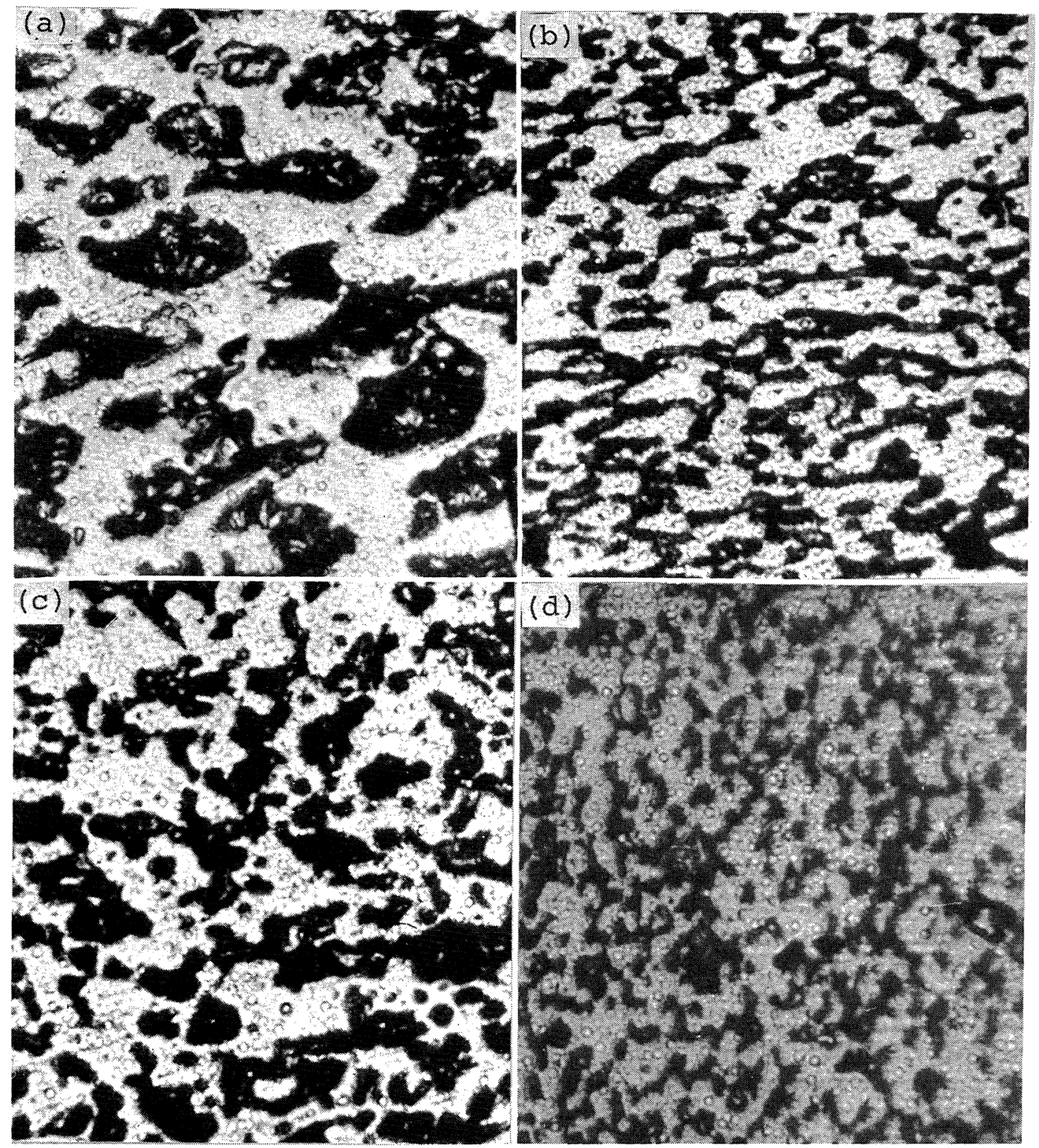

Photo. 4 Microstructural changes for a specimen with planarlinear orientation due to superplastic deformation. Initial: (a) longitudinal (b) transverse. After 135\% elongation: (c) longitudinal $(d)$ transverse $(\times 500)$.

tion. It can be seen that the microstructure tends to become equiaxed with superplastic deformation. The changes in microstructural parameters due to deformation are shown in Table 2 for specimens of different orientations.

\section{Discussion}

The existence of banded structures similar to the ones observed in this study are common among many superplastic alloys ${ }^{(7)(8)}$ in the hot worked state. The elongated grains have also been reported in the hot worked state in some alloys ${ }^{(4)(9)(10)}$. Thus depending on the processing route adopted, either of these structures is observed in the deformation processed state.

The important feature which distinguishes the non-equiaxed microstructures from equi- 
terms of a single parameter such as grain size with the flow behavior would be adequate. Quantitative correlations must necessarily involve other microstructural parameters such as grain shape, grain aspect ratio, etc. ${ }^{(16)(17)}$ Further complications in modelling their flow behavior arise due to continuous change in the microstructure. No theoretical attempts were made in the literature to evolve suitable constitutive relations for such cases.

\section{Conclusions}

(1) Specimens with non-equiaxed microstructures such as banded structures or those having grains elongated in one or two directions exhibit superplastic behavior with anisotropy in their flow stress.

(2) In the superplastic deformation of the specimens of these non-equiaxed microstructures, strain hardening or softening is observed depending on test temperature and the extent of anisotropy in the microstructure. Such microstructures become unstable leading to the evolution of equiaxed microstructure with increasing strain. These aspects of their flow behavior will have to be taken into account for quantitative correlations with microstructural parameters.

\section{REFERENCES}

(1) J. W. Edington, K. N. Melton and C. P. Cutler: Progress in Materials Science, 21 (1976), 63.

(2) D. M. R. Taplin, G. L. Dunlop and T. G. Langdon: Ann. Rev. Mater. Sci., 9 (1979), 151.

(3) M. Suery and B. Baudelet: Rev. Phys. Appl., 13 (1978), 53.

(4) B. P. Kashyap and G. S. Murty: to be published.

(5) E. E. Underwood: Quantitative Microscopy, Ed. by R. T. DeHoff and F. N. Rhines, McGrawHill Book Company (1968), p. 77.

(6) W. A. Backofen, I. R. Turner and D. H. Avery: Trans. ASM, 57 (1964), 980.

(7) G. Herriot, B. Baudelet and J. J. Jonas: Acta Met., 24 (1976), 687.

(8) M. J. Stowell, J. L. Robertson and B. M. Watts: Metal Sci. J., 3 (1969), 41.

(9) M. Suery and B. Baudelet: J. Mat. Sci., 8 (1973), 363.

(10) H. W. Hayden, S. Floreen and P. D. Goodell: Met. Trans., 3 (1972), 833.

(11) R. H. Bricknell and J. W. Edington: Met. Trans. A, 10A (1979) 1257.

(12) R. Grimes, M. J. Stowell and B. M. Watts: Metals Technol., 3 (1976), 154.

(13) B. M. Watts, M. J. Stowell, B. L. Baikie and D. G. E. Owen: Metal Sci., 10 (1976), 189.

(14) B. M. Watts and M. J. Stowell: J. Mat. Sci., 6 (1971), 228.

(15) M. Cagnon, M. Suery, A. E. Berhardt and B. Baudelet: Acta Met., 25 (1977), 71.

(16) H. C. Chandan and G. S. Murty: Ind. J. Tech., 11 (1973), 742.

(17) N. E. Paton and C. H. Hamilton: Met. Trans. A, 10A (1979), 241. 